\title{
Digital preferences and perceptions of students in health professional courses at a leading Australian university: A baseline for improving digital skills and competencies in health graduates
}

\author{
Kwang Meng Cham, Mary-Louise Edwards, Lisa Kruesi, Tania Celeste, Trent Hennessey \\ University of Melbourne
}

\begin{abstract}
This study aimed to improve understanding of graduate students' digital preferences and perceptions to prepare them for work in the digitally enabled health sector. We surveyed 361 students from five disciplines to create a baseline of their digital capabilities. Results show that students were confident in engaging with day-to-day technologies required for discipline-specific learnings and most were reasonably aware of digital privacy and security. However, only $11 \%$ of the students reported having sufficient university support and services to develop their digital skills and competencies, and only $39 \%$ of the students believed they have the relevant skills for entering the workforce. To improve their understanding in this area, students attended a digital skills and employability workshop that was developed in partnership with teaching specialists, learning and teaching librarians and career services coordinators. Post-workshop findings show that this learning intervention positively impacted students' understanding of their own digital capabilities and increased their awareness of the importance of this core skill for both the university and the workforce. Teaching staff can use these findings to improve student digital learning in health professional curricula, which will contribute to knowledge transfer and communication with digital health employers.
\end{abstract}

Implications for practice or policy:

- Heath professional educators can bridge the gap in digital practices between graduates and the workplace by understanding students' baseline digital skills and competencies and developing targeted learning opportunities within the curriculum to support students' digital confidence, experience, attitudes and understandings of digital practices and digital skills and competencies.

- Students' digital skills and competencies can be enhanced by facilitating dialogue between universities, employers and accrediting bodies in the health sector to set consistent and realistic expectations.

Keywords: digital literacies, professional learning, e-health, digital health, health professional education, large survey

\section{Introduction}

The World Health Organisation (2021, p. 39) defines digital health as "the field of knowledge and practice associated with the development and use of digital technologies to improve health". The European Health Parliament (2016) reported on clinicians' readiness to find digital solutions to increase their time spent with patients, improve their efficiencies in daily work, assist in finding information faster and enhance their communication with other caregivers. The Australian Digital Health Agency (2016) has indicated that health practitioners and consumers display a willingness to adopt digital health technologies and processes to improve services. However, as both reports outline, despite inclination, practitioners have limited digital experiences and lack the confidence in owning digital technologies in the clinical space. Recent Australian research (Edirippulige et al., 2018; Gray et al., 2014; Kenny et al., 2016) has also highlighted challenges with health practitioner confidence in the professional digital environment, or alternately termed the ehealth environment, and how to best prepare health professional graduates to function within a sector undergoing rapid transformation.

Developing future-ready graduates with a range of personal, performative and organisational abilities that not only include but exceed their academic achievements emerged a decade ago as an important focus for universities (Tomlinson, 2008). Despite arguments that percolate about university degrees losing their value 
(Pennington \& Stanford, 2019), universities have always prepared students for the world of work (Bhagra \& Sharma, 2018; Henderson et al., 2015) and they are the preferred learning environments for developing digital health programs from early education training to workforce participation (European Health Parliament, 2016). Institutional approaches to digital literacy, digital practices, digital systems, digital technologies and tools have been heavily discussed by researchers and policymakers as transformational for universities (Beetham \& Sharpe, 2013) or at times disruptive to higher education (Coldwell-Neilson, 2017; Johnson et al., 2016). Either way, ensuring that learning is innovative and relevant to the digitally connected world of work, in this case the health sector, still poses a significant challenge in vocationally focused courses (Coldwell-Neilson, 2017).

Student use of digital tools and technologies and perceptions of digital skills relevant to study and achievement in the workplace have been reported previously (Beetham et al., 2019; Coldwell-Neilson, 2017; Kenny et al., 2016; Pennington \& Stanford, 2019; Tomlinson, 2008; Wells, 2011). Research examining digital preparedness of graduates entering the health sector has identified gaps between students' actual digital skills and competencies and the requirements of digital or e-health practices (Edirippulige et al., 2018; Gray et al., 2014; Kenny et al., 2016; Knight \& Drysdale, 2020). Although e-health competencies are represented in international guidelines and accrediting bodies such as the Australian Medical Council, coverage of health information technologies is often vague or generalised, and is isolated from, rather than integrated with, vocational learning programs (Smith et al., 2020).

In addition, it remains questionable if students' everyday technological skills accurately reflect their digital capabilities in learning environments (Kennedy et al., 2008). The use of social media in e-health practices is a case in point. Growing numbers of health professionals and organisations now encourage the use of social media to facilitate peer-to-peer information sharing on clinical cases and thus are developing recommendations for social media adoption to be consistent with professional standards and accreditation (Pearson et al., 2015). Even so, the habitual use of personal devices to support learning outside the classroom context does not improve student use and creation of digital artefacts within the curriculum (Beetham et al., 2019).

In our study, we examined students' digital skills and competencies to create a baseline for educators to use this information to design targeted classroom activities and ensure these skills and competencies are relevant to health sector requirements (Smith et al., 2020). The importance of digital practices for learning within the university and for professional and career development was also investigated. This active research is situated in the learning space of feedback and exchange between student and teacher towards the development of clinical learning programs that can support digital communication competencies and new professional expectations (Henderson et al., 2015). To this effect, we included content in a digital skills and employability workshop intervention that addressed individual management of social media profiles to professional standards. Other inclusions highlighted platforms for accessing or engaging the best audience for professional messaging, dissemination of information and lasting implications of digital footprints (Smith et al., 2020).

Importantly, this study contributes a comprehensive survey instrument that can establish baseline levels of students' digital skills and competencies in health. It also examined the effectiveness of a workshop designed as a learning intervention to develop students' digital skills and competencies from baseline levels. As such, this study will support the emerging data around student confidence, experiences, attitudes and understandings of digital practices (Henderson et al., 2015) and create dialogue between universities, employers and accrediting bodies (Edirippulige et al., 2018). Educators will be able to apply these findings to augment the development of health professional graduates' digital capabilities that are applicable to the healthcare sector, thereby achieving meaningful clinical outcomes for consumers and clinicians (Beleigoli et al., 2019).

\section{Digital skills and competencies}

Reflecting the emergent nature of this research field, multiple overlapping terms exist in the literature, including digital literacy or digital literacies (Lankshear \& Knobel, 2008), digital skills and digital competence (Vuorikari et al., 2016), information and communication technology skills, and Internet skills and information literacy (Ilomaki et al., 2016; van Deursen \& van Dijk, 2010; Zhong, 2011). The base concept of digital skills and competence has evolved from the capacity to perform certain technical tasks 
to the capacity to understand, integrate and utilise the information available on any digital device derived from many sources and in a wide variety of formats (Bawden, 2008; Daniel et al., 2015; Vuorikari et al., 2016). In the health services sector, terms commonly used for applications of digital technologies include e-health or digital health services (Edirippulige et al., 2018), with these terms used interchangeably in this article to refer to the professional digital environments in which health practitioners work.

In a recent study of student confidence in digital environments, Bond et al. (2020) discussed digital literacies as encapsulating a merging of technologies, attitudes and capabilities. They reported that in a university context, digital technologies encompass a myriad of hardware and software devices that facilitate communication and access, transmission and storage of information and knowledge in a digital environment. This framing of digital literacy is also apparent in Wells' study (2011) of social media in a health education context. Wells (2011) defined digital literacy as an understanding of an essential set of competencies for students to acquire whilst at university, which include the ability to effectively and critically navigate, elaborate and create information using a range of technologies. Although there is growing support for this more complex understanding of digital literacies in the literature, there is not a clear or comprehensive understanding about the specific sets of skills relating to the use or integration of digital technologies for study or the workplace (Coldwell-Neilson, 2017). Given that studies in the literature tend to be undertaken as either macro-level investigations of organisations, regions and countries or microlevel studies of students (Blayone, 2018), this study was designed as the latter and attempted to addresss the research gap of understanding the specific digital skills and competencies of professional health students in Australia.

\section{Methodology}

\section{Approach}

Using an action research approach which aims to improve practice through a cyclical process of action, evaluation and critical reflection (Lingard, et al., 2008), we sought to understand health professional students' existing knowledge of digital skills and competencies in order to improve the design and delivery of digital learning activities and opportunities within the health professional education curricula. A survey technique was chosen to provide qualitative and quantitative data as it was most suited to the participatory action research approach. This research focused on collection of course-level data rather than on specific academic levels of the participants.

\section{Participants}

This study was approved by the School of Health Sciences Human Ethics Research Committee (ID: 1750872). All students gave informed consent for participating. An online survey was administered to students before and after participation in a learning intervention workshop that focused on their understanding and awareness of digital skills and competencies for learning whilst at university and for use in the health sector workforce. The surveys and workshop were undertaken by health professional students in dentistry, optometry, oral health, physiotherapy and speech pathology at a leading Australian university between 2018 and 2019. All students involved in the study were engaged in learning through clinical programs rather than in independent research investigations.

\section{Pre-workshop intervention survey}

The pre-workshop intervention survey (see Appendix) asked students to indicate responses on 5-point Likert scales and open-ended questions. Questions were clustered across five category types, as described below:

- Demographic data and access to technologies and frequency of use (Questions 1-5)

This category focused on access and regular use of digital technologies and the Internet. Students selected from a checklist of tools to indicate the range of technologies they used. Frequency of use was indicated by selecting from a 6-point frequency scale. 
- Themes of confidence, willingness to learn and the importance of digital skills and competencies for career and professional development (Question 6)

The second category asked students to indicate responses across the three themes. A checklist of 24 digital technologies and their creative uses, mapped to a 5-point Likert scale, required students to rate their levels of confidence in using and creating with digital technologies in a learning and research context at the university. The same checklist and context also pertained to the remaining two themes - willingness to learn and understanding the importance of digital skills and competencies to career and professional development.

- Social media preferences and use and the management of online privacy and security (Questions 7-10)

In this category, students were asked about their use and frequency of social media platforms. They chose from a list of reasons for engagement on social media and were also asked to rate their awareness of the lasting nature of digital material and how well they managed their privacy and security online.

- Definition of the term digital skills and competencies (Question 11)

Students were asked to expand on their understanding of the term digital skills and competencies.

- Importance of digital capabilities for career and professional development and knowledge and perceptions of support they receive from the university in developing such capabilities (Questions 12-17)

In this final category, students were asked if they had developed and achieved the relevant digital skills and competencies during their course of study, if they possessed the digital skills when entering the workforce and if they had received sufficient university support and services in developing their digital skills and competencies. The survey concluded with a free-text comment.

Initially, a research assistant performed a thematic analysis of the definitions of digital skills and competencies. We then independently reviewed and familiarised ourselves with the data to generate relevant codes. Themes were reviewed and refined until agreement was reached (Braun \& Clarke, 2006). Based on the pre-workshop intervention survey results, we developed a targeted digital skills and employability workshop to address students' needs.

\section{Workshop intervention}

The content was delivered face-to-face via presentation slides interlaced with live polling questions as the main interactive component. The workshop introduced the concept of digital wellbeing (impact of technology and what that means for wellbeing), general digital literacy concepts and specific digital health information. Social media policies were discussed using relevant discipline-specific, university and government websites and resources. Search engines, browsers and the concept of the filter bubbles were covered, and techniques were taught to secure online accounts and data. We also covered the essentials of employability skills, building and managing a professional online identity, how to maximise their marketability and keeping up to date with employability trends.

We delivered the workshop separately for each of the five health professional courses. The same cohort of students was then surveyed a week later to evaluate the outcomes of the learning intervention (Table 1). They were asked to re-define the term digital skills and competencies to enable comparison of students' understanding pre- and post- workshop interventions. We performed the same thematic analysis for the post-workshop intervention definitions as outlined earlier when analysing the definitions of the preworkshop intervention. 
Table 1

Post-workshop intervention questions

\begin{tabular}{|c|c|c|c|c|c|}
\hline Questions & $\begin{array}{l}\text { Strongly } \\
\text { agree }\end{array}$ & Agree & Neither & Disagree & $\begin{array}{l}\text { Strongly } \\
\text { disagree }\end{array}$ \\
\hline \multicolumn{6}{|l|}{$\begin{array}{l}\text { The workshop has increased my } \\
\text { understanding and awareness in } \\
\text { digital skills and competencies. }\end{array}$} \\
\hline my strengths and weaknesses in & & & & & \\
\hline $\begin{array}{l}\text { I have a better understanding of the } \\
\text { importance of being digitally } \\
\text { competent. }\end{array}$ & & & & & \\
\hline \multicolumn{6}{|l|}{$\begin{array}{l}\text { I have a better understanding of the } \\
\text { importance of managing my online } \\
\text { identity, privacy and security. }\end{array}$} \\
\hline \multicolumn{6}{|l|}{ I have a better understanding of the } \\
\hline \multicolumn{6}{|l|}{$\begin{array}{l}\text { I am more confident in preparing and } \\
\text { applying for a job in future. }\end{array}$} \\
\hline $\begin{array}{l}\text { Activities involving digital skills and } \\
\text { competencies should be } \\
\text { incorporated into the curriculum. }\end{array}$ & & & & & \\
\hline $\begin{array}{l}\text { Activities involving future career } \\
\text { opportunities should be } \\
\text { incorporated into the curriculum. }\end{array}$ & & & & & \\
\hline $\begin{array}{l}\text { I think there is sufficient University } \\
\text { support and services in developing } \\
\text { my digital skills and competencies. }\end{array}$ & & & & & \\
\hline $\begin{array}{l}\text { I think there is sufficient University } \\
\text { support and services in exploring } \\
\text { career opportunities. }\end{array}$ & & & & & \\
\hline
\end{tabular}

The cyclical process and interplay of action through the workshops and post evaluation of the surveys concluded with critical reflection is reported in the Results, Discussion and Implications for practice sections.

\section{Results}

This section reports on students' perceived understanding of digital skills and competencies and how they defined it pre- and post-workshop interventions.

\section{Pre-workshop intervention}

- Demographic data and access to technologies and frequency of use (Questions 1-5)

A total of 361 students took part in the study, with most participants being female and between 18 to 24 years of age $(68 \%)$. More than half of the responses $(56 \%)$ came from students in optometry, followed by dentistry (16\%), speech pathology (14\%), oral health $(11 \%)$ and physiotherapy (3\%). The two most commonly used digital technologies were a smartphone (39\%) and a laptop (35\%). We found that $98 \%$ of the students engaged with at least one digital tool several times a day. Of the students surveyed $1 \%$ do not have access to broadband or Wi-Fi Internet at home. 
- Themes of confidence, willingness to learn and the importance of digital skills and competencies for career and professional development (Question 6)

As it was not conducive to simply present three checklists of 24 items, we independently reviewed the data and each of us produced a global summary of what was considered as the most relevant and meaningful items to report in the context of this research and the broader literature. The notes were compared and discussed and overlapping items were identified. The items were then arranged in order of relevance and categories were combined to form three sections (very or reasonably confident; somewhat confident; a little or not confident) for reporting. The responses for the somewhat confident category across all items were not meaningful, having ranged between $2 \%$ to $28 \%$. As such, we have decided not to report the findings for this category. The results are presented in the following format: very or reasonably confident (Table 2), a little or not confident (Table 3), a desire to learn the technology (Table 4), and the importance of attaining a specific digital skill (Table 5).

Table 2

Very or reasonably confident

\begin{tabular}{lc}
\hline Technology & Response \\
\hline Using email & $97 \%$ \\
Using learning management system & $93 \%$ \\
Using video conferencing tools (e.g., Skype, FaceTime) & $88 \%$ \\
Using word processing software & $86 \%$ \\
Using presentation software (e.g., PowerPoint, Prezi) & $83 \%$ \\
Using file-sharing and storage (e.g., Google Drive, Dropbox) & $81 \%$ \\
\hline
\end{tabular}

Table 3

A little or not confident

\begin{tabular}{lc}
\hline Technology & Response \\
\hline Using geospatial technologies (e.g., FalconView, GeoDa) & $91 \%$ \\
Using data visualisation tools (e.g., Tableau, Qilkview) & $88 \%$ \\
Using curation tools (e.g., Diigo, Scoop.it) & $85 \%$ \\
Using 3D printing & $84 \%$ \\
Creating computer programs & $92 \%$ \\
Creating applications & $90 \%$ \\
Creating e-books, self-publishing & $84 \%$ \\
\hline
\end{tabular}

Table 4

A desire to learn the technology

\begin{tabular}{lc}
\hline Technology & Response \\
\hline Using 3D printing & $44 \%$ \\
Using reference management software (e.g., Endnote, Mendeley) & $39 \%$ \\
Using augmented and virtual reality & $36 \%$ \\
Creating websites & $50 \%$ \\
Creating applications & $46 \%$ \\
Creating graphics and images & $38 \%$ \\
Creating audio-visual production & $36 \%$ \\
\hline
\end{tabular}

Table 5

The importance of attaining a specific digital skill

\begin{tabular}{lc}
\hline Skill & Response \\
\hline Using spreadsheet software & $40 \%$ \\
Using reference management software (e.g., Endnote, Mendeley) & $40 \%$ \\
Using word processing software & $39 \%$ \\
Using presentation software (e.g., PowerPoint, Prezi) & $38 \%$ \\
Using file-sharing and storage (e.g., Google Drive, Dropbox) & $35 \%$ \\
Creating websites & $33 \%$ \\
Creating e-books, self-publishing & $31 \%$ \\
\hline
\end{tabular}


- Social media preferences and use and the management of online privacy and security (Questions 7-10)

More than $90 \%$ of the students utilised Facebook and YouTube as the main social media tools and $72 \%$ reported engaging with them several times a day. The purposes for usage included learning and research (43\%), social purposes (35\%) and for career and professional development (22\%). Of the students, 32\% chose LinkedIn to build their professional online identity. Only $69 \%$ of the students were reasonably aware of the lasting nature of digital material and knew how to manage their digital privacy and security.

- $\quad$ Definition of the term digital skills and competencies (Question 11)

From the students' perspectives, they defined the term as "the ability to use technology efficiently" (69\%), "using it for education and career purposes" (18\%) or "for social purposes" $(13 \%)$.

- Importance of digital capabilities for career and professional development and knowledge and perceptions of support they receive from the university in developing such capabilities (Questions 12-17)

Of the students, $81 \%$ highlighted that attaining competency in digital skills would enhance their career and professional development but only $39 \%$ believed they possessed the relevant skills for entering the workforce. Only $11 \%$ of the students reported having sufficient university support via library services and resources, attending workshops and learning digital skills through course assignments. A total of $56 \%$ of the students were unsure if university support was sufficient.

When asked what the university needed to do to help students succeed in achieving these digital capabilities, students provided three main suggestions: that the university incorporates the learning of digital skills into the health professional curricula, provides online modules and workshops and creates specialised digital training courses relevant to students' fields of study and prospective careers.

\section{Post-workshop intervention}

During the workshop, we observed that student responses to the poll questions showed high levels of participation but diffuse levels of understanding regarding the topics covered. Only $43 \%$ of the students completed the post-workshop intervention survey (Table 6). High internal consistency and reliability of the responses were indicated by a Cronbach's alpha of 0.98 . The median score was 4 (out of 5) for all questions, suggesting that the workshop was beneficial. Of the students $83 \%$ strongly agreed or agreed that the workshop had increased their understanding and awareness in digital skills and competencies. More than $85 \%$ of the students understood the importance of being digitally competent and managing online identity, privacy and security, with $75 \%$ being able to identify their strengths and weaknesses in this area. A total of $79 \%$ of the students proposed that activities involving digital skills and competencies should be incorporated into the curriculum, while $90 \%$ of them suggested future career opportunities should be covered as well. Of the students, 52\% believed there is sufficient university support and services in developing their digital skills and competencies.

When students were asked to re-define the term digital skills and competencies, they defined it as "the informed use of technology" (36\%), followed by "the ability to protect online privacy and security" (32\%), "purposeful use of technology" (21\%), "skills that increase connectivity" (10\%) and "the ability to build a professional digital identity" (1\%). 
Table 6

Post-survey findings

\begin{tabular}{|c|c|c|c|c|c|}
\hline Questions & $\begin{array}{l}\text { Strongly } \\
\text { agree }\end{array}$ & Agree & Neither & Disagree & $\begin{array}{l}\text { Strongly } \\
\text { disagree }\end{array}$ \\
\hline $\begin{array}{l}\text { The workshop has increased my } \\
\text { understanding and awareness in } \\
\text { digital skills and competencies. }\end{array}$ & $25 \%$ & $58 \%$ & $13 \%$ & $2 \%$ & $2 \%$ \\
\hline $\begin{array}{l}\text { The workshop has helped me identify } \\
\text { my strengths and weaknesses in } \\
\text { digital skills and competencies. }\end{array}$ & $20 \%$ & $55 \%$ & $18 \%$ & $6 \%$ & $1 \%$ \\
\hline $\begin{array}{l}\text { I have a better understanding of the } \\
\text { importance of being digitally } \\
\text { competent. }\end{array}$ & $24 \%$ & $62 \%$ & $10 \%$ & $2 \%$ & $2 \%$ \\
\hline $\begin{array}{l}\text { I have a better understanding of the } \\
\text { importance of managing my online } \\
\text { identity, privacy and security. }\end{array}$ & $40 \%$ & $50 \%$ & $7 \%$ & $2 \%$ & $1 \%$ \\
\hline $\begin{array}{l}\text { I have a better understanding of the } \\
\text { range of available career options. }\end{array}$ & $12 \%$ & $39 \%$ & $25 \%$ & $17 \%$ & $7 \%$ \\
\hline $\begin{array}{l}\text { I am more confident in preparing and } \\
\text { applying for a job in future. }\end{array}$ & $14 \%$ & $44 \%$ & $27 \%$ & $9 \%$ & $6 \%$ \\
\hline $\begin{array}{l}\text { Activities involving digital skills and } \\
\text { competencies should be } \\
\text { incorporated into the curriculum. }\end{array}$ & $17 \%$ & $62 \%$ & $17 \%$ & $3 \%$ & $1 \%$ \\
\hline $\begin{array}{l}\text { Activities involving future career } \\
\text { opportunities should be } \\
\text { incorporated into the curriculum. }\end{array}$ & $40 \%$ & $50 \%$ & $7 \%$ & $2 \%$ & $1 \%$ \\
\hline $\begin{array}{l}\text { I think there is sufficient University } \\
\text { support and services in developing } \\
\text { my digital skills and competencies. }\end{array}$ & $9 \%$ & $43 \%$ & $30 \%$ & $13 \%$ & $5 \%$ \\
\hline $\begin{array}{l}\text { I think there is sufficient University } \\
\text { support and services in exploring } \\
\text { career opportunities. }\end{array}$ & $7 \%$ & $42 \%$ & $31 \%$ & $14 \%$ & $6 \%$ \\
\hline
\end{tabular}

\section{Discussion}

This study examined the understanding of digital skills and competencies at course level (Armah \& Westhuizen, 2020; Beetham et al., 2019), particularly focusing on the digital experiences and practices of university students within health professional disciplines. In adopting an action research approach, it further examined the efficacy of a workshop as a learning intervention to build evidence for embedding vocationally relevant digital competencies into the curriculum.

\section{Students' digital skills and competencies to support their learning}

We found that this cohort of students tended to be active and routine digital users, reporting high levels of confidence using day-to-day digital tools for learning and exhibiting a preference for using mobile devices (smartphones and laptops) rather than fixed desktop workstations. Unsurprisingly, frequency of use and confidence were highest for essential technologies such as the learning management system to navigate, communicate, upload and manage information; email for asynchronous communication; word processing software for writing and note-taking; presentation software for seminars; and file-sharing and storage for resource compilation.

However, mixed levels of digital confidence and skills were evident across the sample, which is problematic for student learning outcomes given the use of technology is largely governed by course and university requirements (Jones, 2012). For example, 39\% of the students indicated they would like to learn how to use reference management software, which is a skill they viewed as important to attain. Although students generally reported feeling confident with video-conferencing tools, it is worth noting that the data were collected before the COVID-19 pandemic, and as such may not fully represent students' confidence in 
wholescale online learning in the current context. Students also reported low confidence in digital technologies not specific to their coursework, such as using geospatial technologies or creating computer programs. Reflecting the asymmetric levels of willingness to learn digital capabilities across the cohort, it is important to observe that a proportion of students reported a positive attitude and willingness to engage with technologies that might be implicit for their study, if given the opportunities (e.g., using 3D printing or creating applications). Considered together, these findings caution against making blanket assumptions about digital native learners' technology-related skills and preferences (Smith et al., 2020).

\section{Vocational applications of students' digital skills and competencies}

When students were asked to indicate technologies and related skills and competencies as important for enhancement of their career and professional development, most of the tools overlapped with the daily technologies used for study. Despite this overlap, students highlighted that further attainment of competency in digital skills would enhance their career and professional development as few believed they possessed the relevant skills for entering the workforce. Overwhelmingly, $90 \%$ of students strongly agreed or agreed that future career opportunities should be incorporated into the curriculum. This finding supports the call from Beleigoli et al. (2019) to increase the incorporation of digital tools and technologies into clinical learning for both health students and professionals as a key driver to improving clinical practice and patient care.

Although students generally understood the applicability of digital skills and competencies from their current learning context to their future vocational context, this transferability was not as clearly developed for digital skills and competencies predominantly developed in a social context. For example, students tended to report high usage levels of social media platforms (e.g., Facebook and YouTube) which they used in both social and learning contexts. Although social media capabilities should be valued as part of students' funds of knowledge, which they bring with them to university (Gonzàlez et al., 2005), students did not widely connect their social media skills and knowledge to future career purposes. This finding suggests students' immediate preoccupation with their studies and university context may have limited the social to professional learning transfer regarding their digital skill and competencies. Interestingly, students reported only moderate levels of understanding about the related competencies of digital privacy and security, prompting us to include managing digital footprints as a topic in the intervention workshop to improve the transfer of learning about digital skills and competencies across students' social, learning and professional contexts.

\section{Responses to low awareness of learning opportunities to develop digital skills and competencies}

Across the cohort, most students reported being unsure about the available service offerings and learning opportunities to develop their digital capabilities at the university. These low levels of awareness likely contributed to students' perceptions that that there were insufficient university services to assist them to develop their digital skills and competencies. However, we observed a significant increase from $11 \%$ to $52 \%$ of the students stating there is sufficient university support after the workshop intervention, presumably based on their increased awareness. Although this awareness problem may be the outcome of limited or ineffective promotion of these digital services to the students, another contributor may be the peripheral focus on digital skills and competencies within their course, with this knowledge and skill domain being part of the informal curriculum. To improve learning outcomes, digital skills and competencies need to be integrated and contextualised into discipline-specific learning and addressed through curriculum objectives (Johnson et al., 2016). However, the digital skills development within health professional curricula are largely implied and not explicitly articulated to students. Interestingly, a national study conducted by Edirippulige et al. (2018) outlined impediments to incorporating e-health skills and competencies into medical education in Australia. The impediments uncovered include the crowded curriculum and competing priorities for inclusion of new topics, a perceived lack of support from the health systems in which students gain experiential learning and a lack of demand from accrediting bodies. We propose that these impediments are similarly present within health professional education. 


\section{The efficacy of a workshop intervention for building awareness about digital skills and competencies}

When analysing students' definition of digital skills and competencies pre- and post-workshop interventions, the post-definitions collectively demonstrated more nuanced understandings that reflected awareness of the importance of digital presence and the purpose of these skills and competencies beyond their personal needs. It has previously been noted that a key challenge for universities and teaching staff is developing students' digital competencies from a varied base of experience and confidence to meet the digital demands of future jobs (Vuorikari et al., 2016). Comparison of the pre- and post-workshop responses supports the efficacy of even a single-shot workshop as a form of learning intervention that was effective in stimulating participant discussion and reflection about their current and desired digital skills and competencies, and how these skills and competencies impact their employability and future work practices in e-health. Understanding that high levels of digital skills and competencies enable students to make better career choices and find quality jobs (Blayone, 2018; Vuorikari et al., 2016), this study supports the potential for more student-centred and vocationally focused digital capability building to be integrated into the current health professional curricula.

\section{Implications for practice}

This research supports the need for institution-, course- and subject-level initiatives to be implemented to better understand and improve health students' digital skills and competencies. At an institutional level, teaching and professional staff where possible must work together to effectively promote the availability of digital skills and competency services and resources to students. Achieving greater visibility and improved accessibility of these student support services and resources is foundational to increasing low levels of awareness about them, and in turn, increasing service uptake and learner engagement.

At a course-level, we encourage health educators to first understand new students' uses and perceptions of their digital skills and competencies and then use this baseline as a starting point to design a scaffolded whole-of-course digital learning program within curricula. To this end, resources such as ColdwellNeilson's (2017) framework and the digital competence framework developed by Vuorikari et al. (2016) may serve as a useful resource for educators, providing them with comprehensive descriptions of digital skills and competencies for learning that can be adapted and applied to specific disciplinary and vocational contexts. Importantly, course coordinators must engage with employers and accrediting bodies when establishing descriptions and measures of discipline-specific digital skills and competencies in health. This triangulation is required to capture the new and emerging skills and knowledge of rapidly evolving e-health services, as well as ensuring there is broader alignment between a health course's digital learning program and practitioner accreditation requirements. We recommend that course coordinators make digital skills and competencies clear and explicit to health students by embedding them into the learning objectives and graduate attributes of their courses and integrating them in curricula and assessment.

Even if there are limited institution- and course-level initiatives, this study supports the efficacy of subjectlevel initiatives (such as an interactive workshop) to generate dialogue that stimulates health students' reflexivity and improves their understanding and awareness of the importance of their digital skills and competencies. We urge teaching staff to use iterative learning design processes to co-design their learning interventions with students, with activities and outcomes informed by pre- and post-workshop surveys, learner feedback and observations (Hayman \& Smith, 2015). In this way, teaching staff can act as change agents, helping to overcome the identified internal barrier of a crowded health curricula (Edirippulige et al., 2018) which has relegated students' digital skills and competencies to the periphery in the design of some health courses and subjects. As such, we recognise the vital role that health educators play at a subjectlevel, with their willingness to explore students' digital skills and competencies enabling the next generation of practitioners to continue advancing e-health, and trailblaze better health services and practices in a digital world at large. 


\section{Limitations and future research}

This study explored student perceptions and experiences as a starting point for understanding graduates' digital skills and competencies within a health professional curriculum. At course level, whilst digital competencies can be surveyed to better understand confidence and readiness (willingness to learn), pursuing the development of digital skills and competencies with such a narrow focus may be limiting for students, and can also result in inconsistencies even across similar fields such as those within health professional courses (Blayone, 2018). To meet the challenges of learning and employment in the health sector, more active research approaches need to be aimed at meaningful, contextual and scaffolded development of digital skills and competencies (Stokes, 2017).

Although the current study included participants from five health disciplines, the sample was skewed to optometry students and was conducted at a single institution. Future research should consider having larger sample sizes for the remaining four professions and incorporate other health professional disciplines from other universities. Semi-structured interviews or focus groups could be conducted to gain a deeper insight into students' desire to learn other digital technologies that might not be directly relevant in their field. The relevance and applicability of the e-health skills learnt at university and how that translates into the future workplace is also worth investigating. More work into addressing the support for the design and embedding of digital skills and competencies within academic disciplines to prepare students for their careers is still needed (Knight \& Drysdale, 2020). A curriculum review of health professional courses, mapping the digital skills and competencies to accreditation frameworks and implementing pre- and post-assessment interventions will be beneficial for identifying the gaps in this area.

Preparing students for future employability is consistently linked to feedback from professions and driven in part by national and international labour market demands (Bhagra \& Sharma, 2018). This has been particularly evident in vocationally focused, clinical practice courses such as those in health and education (Pennington \& Stanford, 2019). Therefore, we envisage that there is a need to consult teaching staff, accreditation bodies and prospective employers to identify the digital interplay between these key stakeholders. In this way, staff will be empowered to teach relevant digital skills that will enhance students' future employability, and in alignment with accreditation frameworks.

\section{Conclusion}

This study provides, for the first time, critical and relevant baseline information about health professional graduates' digital preferences and perceptions. By adopting a more comprehensive perspective about digital literacies, it not only captured students' current technology use and practices but their digital confidence, experience, attitudes and understandings in relation to both their studies and careers as health professionals. Although students' digital skills and competencies require continual monitoring with critical incremental shifts to improve the learning experience (Kenny et al., 2016), this study revealed the efficacy of creating baseline information about students' digital literacies and using it to design targeted learning interventions. The complexity and challenges of building students' digital skills and competencies are significant for health educators, but they are not insurmountable obstacles that should be relegated to the periphery in lieu of an evidence-based way forward. This study affirmed that even single-shot workshops can be effective learning interventions that generate student dialogue, reflexivity and understanding about their digital literacies and its importance to their future work as health professionals. All health educators can be empowered to similarly design baseline information gathering activities and learning interventions as part of the collective efforts by health educators to create explicit recognition for, and greater prioritisation of, digital literacies in health curricula. Equipping students to navigate the digital transformation underway in learning and health is core for student success and foundational to health educator's responsibilities to accrediting bodies and employers. The potential benefits of digital transformation for patient care across the health sector demand a continued focus on how health education can evolve to equip the next generation of health professionals with the digital skills and competencies they need to work effectively, safely and productively in e-health. 


\section{Acknowledgements}

We wish to thank all students for participating in the study and the instructors (Kathy Ryan, Kathryn Frame and Warren Frehse) for developing and delivering the workshop.

\section{References}

Armah, J. K., \& Westhuizen, D. D. (2020). Embedding digital capability into the higher education curriculum: The case of Ghana. Universal Journal of Educational Research, 8(2), 346-354. https://doi.org/10.13189/ujer.2020.080203

Australian Digital Health Agency. (2016). Australia's national digital health strategy: Safe, seamless and secure. https://www.digitalhealth.gov.au/about-us/national-digital-health-strategy-and-framework-foraction

Bawden, D. (2008). Origins and concepts of digital literacy. In C. Lankshear \& M. Knobel (Eds.), Digital literacies: Concepts, policies and practices (pp. 17-32). Peter Lang.

Beetham, H., Newman, T., \& Knight, S. (2019). Digital experience insights survey 2018: Findings from Australia and New Zealand university students. Joint Information Systems Committee. https://www.jisc.ac.uk/reports/digital-experience-insights-survey-2018-students-anz

Beetham, H., \& Sharpe, R. (Eds.). (2013). Rethinking pedagogy for a digital age. Routledge. https://doi.org/10.4324/9781351252805

Beleigoli, A. M., Maeder, A., Button, D., Lange, B., \& Tiemann, J. (2019). The care informatics and technologies project: Enhancing capability, motivation and opportunities in digital health among health professionals and students. In E. Cummings, M. Merolli, \& L. K. Schaper (Eds.), Studies in health technology and informatics: Vol. 266. Digital health: Changing the way healthcare is conceptualised and delivered: Selected Papers from the 27th Australian National Health Informatics Conference, HIC 2019 (pp. 25-29). IOS Press. https://doi.org/10.3233/SHTI190768

Bhagra, A., \& Sharma, D. K. (2018). Changing paradigm of employability skills in the global business world: A review. The IUP Journal of Soft Skills, 12(2), 7-24. https://www.iupindia.in/307/ijss.asp

Blayone, T. (2018). Reexamining digital-learning readiness in higher education: Positioning digital competencies as key factors and a profile application as a readiness tool. International Journal on ELearning, 17(4), 425-451. https://www.learntechlib.org/primary/p/178285/

Bond, M., Buntins, K., Bedenlier, S., Zawacki-Richter, O. \& Kerres, M. (2020). Mapping research in student engagement and educational technology in higher education: A systematic evidence map. International Journal of Technology in Higher Education, 17(2). https://doi.org/10.1186/s41239-019$\underline{0176-8}$

Braun,V., \& Clarke, V. (2006). Using thematic analysis in psychology. Qualitative Research in Psychology, 3(2), 77-101. https://doi.org/10.1191/1478088706qp063oa

Coldwell-Neilson, J. (2017). Digital literacy: A driver for curriculum transformation. In R. G. Walker \& S. B. Bedford (Eds.), Research and development in higher education: Curriculum transformation (vol. 40, pp. 84-94). Higher Education Research and Development Society of Australasia. https://www.herdsa.org.au/research-and-development-higher-education-vol-40-84

Daniel, J., Vazquez-Cano, E., \& Gisbert, M. (2015). The future of MOOCs: Adaptive learning or business model? Universities and Knowledge Society Journal, 12(1), 64-73. https://doi.org/10.7238/rusc.v12i1.2475

Edirippulige, S., Brooks, P., Carati, C., Wade, V. A., Smith, A. C., Wickramasinghe, S., \& Armfield, N. R. (2018). It's important, but not important enough: eHealth as a curriculum priority in medical education in Australia. Journal of Telemedicine and Telecare, 24(10), 697-702. https://doi.org/10.1177/1357633X18793282

European Health Parliament. (2016). Digital skills for health professionals. https://www.healthparliament.eu/wp-content/uploads/2017/09/Digital-skills-for-healthprofessionals.pdf

Gonzàlez, N., Moll, L.C., \& Amanti, C. (Eds.) (2005). Funds of knowledge: Theorizing practices in households, communities, and classrooms. Lawrence Erlbaum Associates. https://doi.org/10.4324/9781410613462

Gray, K., Dattakumar, A., Maeder, A., Henderson, K. B., \& Chenery, H. J. (2014). Advancing ehealth education for the clinical health professions. Australian Government Office for Learning and Teaching. https://ltr.edu.au/resources/PP10_1806_Gray report_2014.pdf 
Hayman, R., \& Smith, E. E. (2015). Sustainable decision making for emerging educational technologies in libraries. Reference Services Review, 43(1), 7-18. https://doi.org/10.1108/RSR-08-2014-0037

Henderson, M., Selwyn, N., Finger, G., \& Aston, R. (2015). Students' everyday engagement with digital technology in university: Exploring patterns of use and 'usefulness'. Journal of Higher Education Policy and Management, 37(3), 308-319. https://doi.org/10.1080/1360080X.2015.1034424

Ilomäki, L., Paavola, S., Lakkala, M., \& Kantosalo, A. (2016). Digital competence-An emergent boundary concept for policy and educational research. Education and Information Technologies, 21(3), 655-679. https://doi.org/10.1007/s10639-014-9346-4

Johnson, L., Adams Becker, S., Cummins, M., Estrada, V., Freeman, A., \& Hall, C. (2016) NMC Horizon report: 2016 Higher education edition. The New Media Consortium. https://library.educause.edu/resources/2016/2/2016-horizon-report

Jones, C. (2012). Networked learning, stepping beyond the net generation and digital natives. In L. Dirckinck-Holmfeld, V. Hodgson, \& D. McConnell (Eds.), Exploring the theory, pedagogy and practice of networked learning. (pp. 27-41) Springer. https://doi.org/10.1007/978-1-4614-0496-5 2

Kennedy, G. E., Judd, T. S., Churchward, A., Gray, K., \& Krause, K.-L. (2008). First year students' experiences with technology: Are they really digital natives? Australasian Journal of Educational Technology. 24(1), 108-122. https://doi.org/10.14742/ajet.1233

Kenny, A., Iacono, T., McKinstry, C., Hannon, J., Knight, K., \& Whitrow, D. (2016). Capabilities for ehealth education: Developing undergraduate digital literacies for health professionals. Department of Education and Training. https://ltr.edu.au/resources/SD14_4377_Kenny_Report_2016.pdf

Knight, G. L., \& Drysdale, T. D. (2020). The future of higher education (HE) hangs on innovating our assessment-but are we ready, willing and able? Higher Education Pedagogies, 5(1), 57-60. https://doi.org/10.1080/23752696.2020.1771610

Lankshear, C., \& Knobel, M. (2008). Digital literacies: Concepts, policies and practices. Peter Lang.

Lingard, L., Albert, M., \& Levinson, W. (2008). Grounded theory, mixed methods, and action research. BMJ, 337, 459-461. https://doi.org/10.1136/bmj.39602.690162.47

Pearson, D., Cooney, R., \& Bond, M. C., (2015). Recommendations from the Council of Residency Directors (CORD) social media committee on the role of social media in residency education and strategies on implementation. Western Journal of Emergency Medicine, 16(4), 510-515. https://doi.org/10.5811/westjem.2015.5.25478

Pennington, A., \& Stanford, J. (2019). The future of work for Australian graduates: The changing landscape of university employment transitions in Australia. The Australia Institute, Centre for Future Work. https://www.futurework.org.au/the_future_of_work_for_australian_graduates

Smith, E., Kahlke, R., \& Judd, R. (2020). Not just digital natives: Integrating technologies in professional education contexts. Australasian Journal of Educational Technology, 36(3), 1-14. https://doi.org/10.14742/ajet.5689

Stokes, J. (2017). Inclusion and engagement by design: Creating a digital literacy course to inspire diverse learners in an Australian university enabling program. International Studies in Widening Participation, 4(2), 65-78. https://novaojs.newcastle.edu.au/ceehe/index.php/iswp/article/view/85

Tomlinson, M. (2008). The degree is not enough: Students' perceptions of the role of higher education credentials for graduate work and employability. British Journal of Sociology of Education, 29(1), 49-61. https://doi.org/10.1080/01425690701737457

van Deursen, A., \& van Dijk, J. (2010). Measuring internet skills. International Journal of HumanComputer Interaction, 26(10), 891-916. https://doi.org/10.1080/10447318.2010.496338

Vuorikari, R., Ferrari, A., Punie, Y., \& Brecko, B. (2017). The digital competence framework for consumers (Joint Research Centre Science for Policy Report, EUR 28133 EN). European Union. https:/doi.org/10.2791/838886

Vuorikari, R., Punie, Y., Carretero Gomez S., \& Van den Brande, G. (2016). DigComp 2.0: The digital competence framework for citizens. Update phase 1: The conceptual reference model (EUR 27948 EN). European Union. https://doi.org/10.2791/11517

Wells, K. (2011). Social media in medical school education. Surgery, 150(1), 2-4. https://doi.org/10.1016/j.surg.2011.05.023

World Health Organization. (2021). Global strategy on digital health 2020-2025. https://apps.who.int/iris/handle/10665/344249

Zhong, Z. (2011). From access to usage: The divide of self-reported digital skills among adolescents. Computers \& Education, 56(3), 736-746. https://doi.org/10.1016/j.compedu.2010.10.016 
Corresponding author: Kwang Meng Cham, ckwang@unimelb.edu.au

Copyright: Articles published in the Australasian Journal of Educational Technology (AJET) are available under Creative Commons Attribution Non-Commercial No Derivatives Licence (CC BY-NC-ND 4.0). Authors retain copyright in their work and grant AJET right of first publication under CC BY-NC-ND 4.0 .

Please cite as: Cham, K. M., Edwards, M.-L., Kruesi, L., Celeste, T., \& Hennessey, T. (2022). Digital preferences and perceptions of students in health professional courses at a leading Australian university: A baseline for improving digital skills and competencies in health graduates. Australasian Journal of Educational Technology, 38(1), 69-86. https://doi.org/10.14742/ajet.6622 


\section{Appendix: Pre-workshop intervention survey}

1. Gender:
$\square \quad$ Male
$\square \quad$ Female
$\square \quad$ Other identities

2. Age:
$18-24$
$25-29$
$30-34$
35-39
40-44
$45-49$
$50-54$
$55-59$
$60-64$
65-69
$70-74$
$75-79$

3. What type of digital equipment do you use (you may select more than one option)?

$\square \quad$ Smartphone (e.g., iPhone)

$\square$ Non-smartphone

$\square \quad$ Tablet (e.g., iPad)

$\square$ Desktop computer

$\square \quad$ Laptop

$\square \quad$ Video camera (e.g., GoPro)

$\square \quad$ Others (please specify:

4. Do you have access to broadband or Wi-Fi Internet at home?
$\square$ Yes
$\square \quad \mathrm{No}$

5. If yes, how often do you access the Internet?
$\square \quad$ Never
Rarely (once a month)
Once a week
Several times a week
Once a day
Several times a day

6. In the following section, indicate how confident you are with creating/using the technology for your learning and research at the University. In addition, if you are not familiar with any of them, would you like to learn how to use this technology? Do you think it is important and useful for you to develop and achieve these skills to enhance career and professional development? 


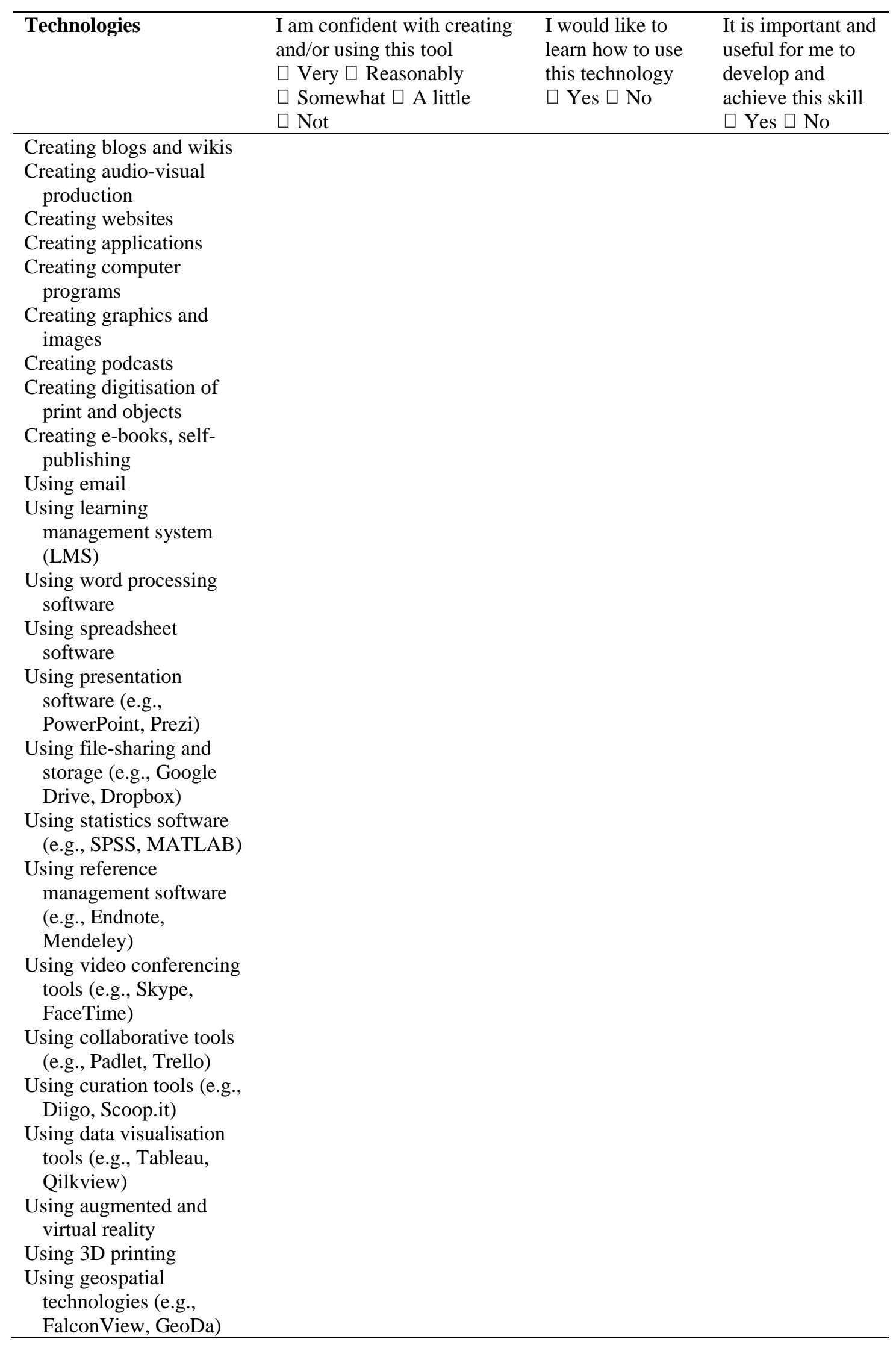


7. Please indicate if you use social media tools for the following activities (you may select more than one option).

Learning

Research

Career and professional development

Social

No, I do not use social media tools

8. If yes, what kind of tools do you use (you may select more than one option)?
$\square$ Pinterest
․ Google+
ㄱickr
口 Vimeo
ㄱacebook
口 Twitter
- YouTube
口 Instagram
$\square \quad$ LinkedIn
$\square$ Other tools (please specify:

9. Please indicate how often you use these online tools.
$\square$ Never
$\square \quad$ Rarely (once a month)
$\square \quad$ Once a week
$\square$ Several times a week
$\square$ Once a day
$\square \quad$ Several times a day

10. I am aware of the lasting nature of digital material, and hence actively manage my security and privacy online.
$\square$ Very
$\square$ Reasonably
․ Somewhat
$\square$ A little
№t
$\square \quad$ Not sure

11. In your own words, what do you understand by the term digital skills and competencies?

12. Do you think possessing digital skills and competencies will enhance your career and professional development?
$\square$ Yes
$\square$ No
$\square \quad$ Not sure

13. Do you think you develop and achieve the relevant digital skills and competencies during your course of study?
$\square$ Yes
$\square$ No
$\square$ Not sure

14. Do you think you have the relevant digital skills and competencies when entering the workforce?
$\square$ Yes
$\square \quad$ No
Not sure 
15. Do you think there is sufficient University support and services in developing your digital skills and competencies?
$\square \quad$ Yes
$\square \quad$ No
$\square \quad$ Not sure

16. If you selected Yes to the previous question, please describe what the University has done to help you succeed in developing and achieving digital skills and competencies. If you selected No/Not sure to the previous question, please describe what the University needs to do to help you succeed in developing and achieving digital skills and competencies.

17. Any other comments? 